\title{
The workplace satisfaction of Romania's medical personnel in state and public institutions
}

\author{
Cristina GHENU \\ The Bucharest University of Economic Studies, Bucharest, Romania \\ cristina.ghenu@man.ase.ro
}

\begin{abstract}
Nowadays the Romanian medical system is facing changes in terms of qualified personnel. Each year a great number of doctors decide to leave Romania in order to conduct practice in other countries with better working conditions. In this situation where doctors are no longer pleased to work in Romanian institutions, can we question the quality of their working environment? This study aims to determine the workplace satisfaction of Romania's medical personnel currently working in private as well as state healthcare institutions. In this process, the study also discloses the inside image of Romanian medical units concerning the quality of the working environment, the quality of communications between subordinates belonging to the same section as well as their relations with their "direct superior", "hierarchic superior" and "senior management". To construct the current research, Romanian medical personnel completed a survey in order to determine their knowledge and judgment regarding their working environment. The research implied two phases: the first phase lasted one month and a half during which 100 medical personnel from a public hospital were selected to answer a survey; the second phase followed and it targeted the application of the same questions on 100 medical personnel working in a private institution. The survey comprised situations of everyday life in which any employee can be found. The results reveal the present situation of Romanian medical personnel, how often, despite of their unpleasant working conditions, they are forced to give their best in order to provide the quality medical treatment that any patient is entitled to. Therefore, the findings (1) reveal the inside image of Romanian hospital's system and (2) offer an empirical foundation for subsequent research and improvement of working environments in Romanian hospitals.
\end{abstract}

Keywords: employee satisfaction, Romanian medical personnel, state hospital, private hospital.

\section{Introduction}

The paper scrutinizes the working environment of Romanian medical personnel activating in state and private healthcare institutions. Targeting their satisfaction, it evaluates the atmosphere of the working environment, relationships with colleagues, superiors and their wage benefits, by answering the research question: What is the difference between the workplace-satisfaction of Romania's medical personnel currently working in private as opposed to the ones working in public healthcare institutions? Consequently the following hypotheses will be tested H1: There is a difference regarding career development opportunities in the private hospitals as opposed to public; H2: There is a difference in the wage gains of private medical workers as opposed to public medical workers; H3: Persons working in private hospitals are happy to be part of a collective as opposed to the persons working in public hospitals; H4: There is a communication between the subordinates and hierarchical levels in private hospitals than in public ones.

Currently, the Health System in Romania is being affected by the increased numbers of doctors leaving the country to work in better conditions. As a result, this massive departure impacts the remaining medical staff patients that require treatment. Unfortunately, some of the most affected areas are the rural ones where the number of hospitals and services diversity are lower than inside the capitol and lately the number of doctors per patients is decreasing. 
Because human resources are a key element for the proper functioning of the Healthcare System in Romania, the study sought to reveal the image behind medical institutions following and analyzing the quality of the working environment and employee satisfaction.

\section{Shortcomings in Romanian medical system}

Although human resources are an essential element for the proper functioning of the health system, Romania faces major imbalances in human resource management. The unsatisfactory working conditions as well as the lack of adequate stimulants eventually lead to a discouraged workforce. The feelings employees experience at job represent the source of the satisfaction or dissatisfaction. Naturally if one's job desires and expectations are met the employees are content. Various dimensions of job satisfaction can be enumerated, among which we focus on the job itself, the wages and the recognition that comes with the job. According to Hellman (1997) and Strachota et al. (2003) concluded that job satisfaction influences the retention and turnover as well as the performance and absenteeism. Zellars' et al. (2001), found that collective efficacy of nurses can be associated with their increased levels of job satisfaction while Khurshid et al. (2005) identified a connection between nurses' dissatisfaction and turnover.

Moreover, Khurshid's et al. (2005) study revealed that factors which affected the medical personnel in terms of satisfaction were: the nature of the feedback they received from patients (positive/negative), the access to the needful equipment and materials and especially the reputation of the institute they were currently working for. However, career development was not overpassed as Timmreck (2001) found that independence, agenda, appointments, clinical decisions as well as professional growth were essential factors in nourishing job satisfaction in health care institutions. Other countries make no exception as the study conducted by Barhem et al. (2010) revealed differences in all dimensions of satisfaction regarding private and public health sectors from UAE. Moreover, it underlined the need for the public sector to improve the employees' level of satisfaction.

Similar, empirical studies conducted within various medical departments show that personality traits, organizational determinants and intellectual quality correlates with job satisfaction. As a result, the migration of Romanian doctors is a component of great interest and its socio-economic relevance concerns its effects on the public health system (Dornescu and Manea, 2013). According to the data obtained by the College of Physicians, the largest departures of doctors from Romania came from the university centers of the country such as Bucharest, Cluj, Iasi, Timis, and found their way to other European countries.

\section{Research methodology}

The research data was gathered in two different phases. The selection criteria were men and women working in private/state hospitals, from the highest rank to the lowest. The first phase lasted one month and a half during which 100 medical personnel from a Romanian state hospital were selected to complete a survey. The second phase followed and it targeted the application of the same survey on 100 medical personnel working in a Romanian private hospital. In both cases, before distributing the survey, several meetings were held in each institution in order to inform the medical personnel about the aspects of the research. Participants were reassured about data confidentiality and offered 5 days to consider their attendance. 
To ease the survey distribution, it was printed and offered to each participant along with an envelope. After the completion of the survey, participants were instructed to place it inside the envelope, seal it and place it inside a mailbox from the emergency room. The survey encompassed a section with 39 standard statements concerning the personnel's opinions and knowledge about the quality of their working environment, the quality of communications between the subordinates belonging to the same section or not, as well as their relations with their "direct superior" (DS), „hierarchic superior" (HS) and „senior management” (SM). Responses were designed in a grid and the following five variants were offered to the respondents for encircling: "totally agree" (TA), "agree" (A), "indecisive" (I), "disagree" (D), "totally disagree" (TD). The box containing the personal data wias trimmed afterwards in order not to allow any association with the respondents.

\section{Outcomes and discussions}

The first objective wanted to establish the medical personnel's opinion regarding the activity performed in the institute: its importance, development of skills and competences, job security, earnings, promotions and overall satisfaction labor. Data shows all 100 workers are passionate about their professional activity. Not only they acknowledge the importance of the institute they are currently employed with, but they also declared themselves satisfied at the end of a day if all obligations are fulfilled. Analyzing the inside climate within each type of institute, Table 1 illustrates, only half of the state workers agreed their institute provides them big chances for promotion, although $80 \%$ believe their job offers good opportunities to enrich their knowledge and professional skills. Also, around 40\% private workers consider to have good chances of promotions while above $70 \%$ of them consider their job position offers great opportunities to enrich knowledge and professional skills. At these statements, the rest of the participants remained mostly indecisive. In both cases above $70 \%$ of the respondents were pleased with the opportunity to participate in decisions concerning their own activity. Unfortunately, the wage gains seem not to be satisfying for state workers, as $60 \%$ express their negativity towards this statement. In both cases over $70 \%$ of the respondents feel secure regarding their position in the institute. Collected data showed no more than $20 \%$ state workers feel most employees are satisfied with their work, as opposed to the approximately 59\% private workers who declare most employees are satisfied with their work.

Table 1. Medical personnel's perception of the institutes' inside climate

\begin{tabular}{|l|c|c|c|c|c|c|c|c|c|c|}
\hline Type of workers in terms of institute: & \multicolumn{5}{|c|}{ State workers } & \multicolumn{5}{|c|}{ Private workers } \\
\hline Variants offered for selection: & TA & A & I & D & TD & TA & A & I & D & TD \\
\hline Good chances of promotion & 20 & 30 & 20 & 15 & 15 & 15 & 26 & 50 & 9 & - \\
\hline $\begin{array}{l}\text { Likely to enrich knowledge and professional } \\
\text { skills }\end{array}$ & 62 & 24 & - & 10 & 4 & 60 & 15 & 10 & 15 & - \\
\hline $\begin{array}{l}\text { Pleased with the opportunity to participate in } \\
\text { decisions concerning their own activity }\end{array}$ & 30 & 40 & - & 10 & 20 & 54 & 37 & 6 & 3 & - \\
\hline $\begin{array}{l}\text { The achieved wage gains are satisfactory } \\
\text { A good sense concerning workplace safety in }\end{array}$ & 42 & 28 & - & 17 & 43 & 70 & 30 & - & - & - \\
\hline institute & & & & 13 & 10 & 38 & 41 & 19 & - & 2 \\
\hline $\begin{array}{l}\text { Good opportunities to develop skills and } \\
\text { professional capabilities }\end{array}$ & 56 & 38 & - & 6 & - & 61 & 26 & 10 & - & 3 \\
\hline Most employees are satisfied with their work & - & 20 & 10 & 44 & 26 & 19 & 40 & 21 & 20 & - \\
\hline
\end{tabular}


Note: HS stands for "hierarchic superior", SM stands for „senior management", TA stands for "totally agree", A stands for "agree", I stands for "indecisive", D stand for "disagree", TD stands for "totally disagree".

Given this information, the next step desired to investigate the relations between medical personnel from the same ward and also the relations with members from other wards (Table 2). The survey registered similarities between the two types of institutions, for over $70 \%$ state and private workers declared to have complete trust in their colleagues and they frequently have work-related discussions with them. However, $90 \%$ of the private workers are part of a beautiful working collective while only 38\% state workers enjoy their working collective. Sadly, over $78 \%$ state and private workers declared "quibbling" is present inside and outside of their working collective. Also, around $60 \%$ state workers and $49 \%$ private workers declare their opinions are not taken into considerations inside the wards and the strong competition between employees seem to be affecting over $80 \%$ state workers and about $50 \%$ private workers. Moreover over $80 \%$ state workers declare their is a good collaboration between their wards whereas in the case of private workers this does not apply for more than 57\%. Despite this, all private workers agree most colleagues they collaborate with are very kind albeit only 56 state workers agreed this statement.

Table 2. Relations and interractions of medical colectives

\begin{tabular}{|l|c|c|c|c|c|c|c|c|c|c|c|}
\hline Type of workers in terms of institute: & \multicolumn{4}{|c|}{ State workers } & \multicolumn{5}{|c|}{ Private workers } \\
\hline Variants offered for selection: & TA & A & I & D & TD & TA & A & I & D & TD \\
\hline Fully trust in my colleagues & 21 & 53 & 16 & 10 & - & 33 & 42 & 25 & - & - \\
\hline Not all opinions are considered & 18 & 42 & - & 37 & 3 & 21 & 28 & 4 & 30 & 17 \\
\hline $\begin{array}{l}\text { Often, quibbling intervene between my } \\
\text { colleagues }\end{array}$ & 33 & 51 & 12 & - & 4 & 6 & 72 & 4 & 18 & - \\
\hline Happy to be part of a beautiful collective & - & 38 & 8 & 54 & - & 65 & 25 & 10 & - & - \\
\hline $\begin{array}{l}\text { Frequent work-related discussions with my } \\
\text { colegues }\end{array}$ & 33 & 45 & 22 & - & - & 83 & 17 & - & - & - \\
\hline $\begin{array}{l}\text { Most of the colleges that I collaborate with are } \\
\text { very kind }\end{array}$ & 26 & 30 & 8 & 21 & 15 & 50 & 50 & - & - & - \\
\hline Wards have good collaboration & 26 & 57 & - & 7 & 10 & 8 & 49 & 36 & 7 & - \\
\hline Strong competition between employees & 45 & 42 & 10 & 3 & - & 12 & 40 & 17 & 24 & 7 \\
\hline
\end{tabular}

Note: HS stands for „hierarchic superior”, SM stands for „senior management”, TA stands for "totally agree", A stands for "agree", I stands for "indecisive", D stand for "disagree", TD stands for "totally disagree".

Moreover, analyzing the relations between the medical subordinates and their direct superior (DS), as illustrated in Table 3, 50\% state workers declared the DS consult them before taking decisions that implicates them, whereas over $65 \%$ private workers agreed this statement. In both types of institute over $60 \%$ respondents agreed the DS is efficient in announcing managerial decisions. All private workers and $60 \%$ state workers declared the DS helps them with personal problem but for state workers the DS encouraged only $10 \%$ of their subordinates to participate in decisions making process while in private institutions they encourage about $40 \%$ subordinates. Only $47 \%$ state workers feel fairly treated by their DS as opposed to the private institutions where $90 \%$ respondents felt good regarding the DS's faireness.

In both institutions the DS is perceived as the person who motivates and pushes subordinates to work at their best but only in case of private institutions the DS supported the subordinates in front of superiors as $40 \%$ state workers entailed the opposite. Around 37\% state workers mistrust the DS which was not the case for any of the private workers. Also about 66\% state workers said DS takes decisions alone and does not allow them to organize their own work as in the case of private workers said 
the opposite. Furthermore, 29\% state workers declared DS conults with the „hierarhical superior" (HS) before taking important decisions as opposed to private institutions where over $80 \%$ said DS conult their HS before taking important decisions.

Table 3. Relations between the subordinates and their direct superior

\begin{tabular}{|l|l|l|l|l|l|l|l|l|l|l|}
\hline Type of workers in terms of institute: & \multicolumn{3}{|c|}{ State workers } & \multicolumn{5}{|c|}{ Private workers } \\
\hline Variants offered for selection: & TA & A & \multicolumn{1}{|c|}{ I } & D & TD & TA & A & \multicolumn{1}{|c|}{ I } & D & TD \\
\hline DS consult us before making decisions & 15 & 36 & 11 & 20 & 18 & 53 & 12 & 20 & 15 & - \\
\hline DS quickly announces management decisions & 40 & 23 & 11 & 16 & 10 & 48 & 42 & - & 10 & - \\
\hline DS helps with personal problems & 21 & 39 & - & 20 & 20 & 54 & 46 & - & - & - \\
\hline $\begin{array}{l}\text { DS encourages subordinates to participate in } \\
\text { decisions making process }\end{array}$ & - & 10 & 11 & 50 & 29 & 12 & 31 & 57 & - & - \\
\hline DS is fair with everyone & 9 & 26 & 18 & 30 & 17 & 48 & 42 & - & 10 & - \\
\hline DS wants us to work as best as we can & 62 & 21 & 3 & 10 & 4 & 54 & 46 & - & - & - \\
\hline Mistrust DS & 12 & 25 & 43 & - & 20 & - & - & 11 & 28 & 61 \\
\hline $\begin{array}{l}\text { DS doesn't allow subordinates to organize } \\
\text { their work }\end{array}$ & 15 & 40 & 11 & 17 & 17 & 28 & - & 18 & 35 & 19 \\
\hline DS support subordinates in front of superiors & 11 & 24 & 25 & 40 & - & 40 & 54 & 6 & - & - \\
\hline DS fairly assess individual performance & 15 & 20 & 30 & 20 & 15 & 56 & 34 & 10 & - & - \\
\hline DS takes decisions alone & 22 & 44 & 20 & 10 & 4 & - & - & 45 & 30 & 25 \\
\hline DS consult with HS before taking decisions & - & 29 & 47 & 11 & 13 & 45 & 37 & 14 & 5 & - \\
\hline
\end{tabular}

PICBE | 415

Note: DS stands for „direct superior”, HS stands for „hierarchic superior”, SM stands for „senior management", TA stands for "totally agree", A stands for "agree", I stands for "indecisive", D stand for "disagree", TD stands for "totally disagree".

By aiming to investigate the relations between employees from the same ward but also from other wards the study pursued to investigate not only the hierarchical superior's attitude but also the attitude of "senior management" (SM) towards its employees (Table 4). About $80 \%$ private workers said HS helps them with personal problems while in the case of state workers this applied only for $40 \%$. The SM does not encourage employees' involvement in the decision-making process and does not consider them as assets of the institute, as stated by over $60 \%$ state workers. Also, they are not very receptive to any ideas and initiatives from employees. Similar, some SM of private institutions also do not encourage their involvement in the decision-making process. Still, they seem to be receptive to employees' ideas and initiatives, as declared by over $50 \%$ of the private workers as they consider each employee as being an asset to their institute. Therefore, $77 \%$ private workers would recommend young people to pursue a career in their institution whereas only $32 \%$ state workers would advise young personnel to join their institute.

Table 4. Employee's relations with senior management and hierarchical superiors

\begin{tabular}{|l|l|l|l|l|l|l|l|l|l|l|}
\hline Type of workers in terms of institute: & \multicolumn{4}{|c|}{ State workers } & \multicolumn{5}{c|}{ Private workers } \\
\hline Variants offered for selection: & TA & A & I & D & TD & TA & A & I & D & TD \\
\hline HS help with personal problems & 20 & 20 & 36 & 19 & 7 & 32 & 48 & 8 & - & 12 \\
\hline $\begin{array}{l}\text { SM encourages employees to involve decision } \\
\text { making process }\end{array}$ & 8 & 8 & 22 & 37 & 25 & 10 & 24 & 23 & 33 & 10 \\
\hline SM receptive to employees ideas and initiatives & 10 & - & 43 & 29 & 18 & - & 51 & 23 & 14 & 12 \\
\hline SM consider each employee is an asset & 10 & 8 & 19 & 52 & 11 & 22 & 35 & 8 & 30 & 5 \\
\hline
\end{tabular}

Source: Author's own research.

Note: HS stands for „hierarchic superior”, SM stands for „senior management”, TA stands for "totally agree", A stands for "agree", I stands for "indecisive", D stand for "disagree", TD stands for "totally disagree".

Taking into consideration the previous answers of the state workers it came not as a surprise to learn that 39 would agree they will immediately leave the hospital if the 
opportunity arises. Still 41 of them declared they disagree and completely disagree with this statement as they would not leave the hospital if such opportunity arises. Private workers also expressed their disagreement in this situation as 52 would not consider leaving the hospital if they would have the opportunity. It seemed in their case only 12 medical employees agreed to immediately leave the hospital if opportunity arises.

Collected data for 200 medical workers registered 15 persons with an age between 19-30, 77 workers between 31-40, 72 between 41-50, 31 between 51-60 years old and 5 workers over 60 years old. On a sample of 121 women and 79 men around 16 registered an income of 1,501-2,300 RON, 47 get paid between 2,301-3,000 RON and 110 receive over 3,000 RON.

\section{Conclusion}

Based on the results the study concludes the first hypothesis verifies for the results registered a small difference regarding career development opportunities the private hospitals offer as opposed to the public one. Moreover, the second hypothesis verifies for the results showed that all private workers were content with their wage gains compared to the 40 working in public hospitals. Further the third hypothesis verifies since 90 persons working in private hospitals are happy to be part of a beautiful collective as opposed to the 30 persons working in public hospitals. Finally, the last hypothesis verifies as 80 private workers have a good relation with their hierarchical superiors while only 40 public workers shared their feelings. Thereby, the research question verifies for differences have been found between state and private hospitals environments in terms of career development opportunities, wage gains, atmosphere of their working collective and the relations with superiors. In comparison with the research elaborated by Khurshid's et al. (2005) that revealed the factors which affected the medical personnel in terms of satisfaction were: the nature of the feedback they received from patients (positive/negative), the access to the needful equipment and materials and especially the reputation of the institute they were currently working for, the present study establishes Romanian medical workers are affected by factors such as interpersonal relations, wage gains and access to career development opportunities.

The current study represents the first part of the research that approaches the subject of workplace satisfaction of Romania's medical personnel from state and private institutions. So far, the study was limited to 200 respondents, as the manual data collection is a complex process that requires time and careful data analysis and interpretation. Obviously, another restriction of the current study is the lack of transparency, aspect that will be approach in the following research by adding another section to the survey that will encompass open questions that will enable the expression of more elaborate personal point of view by focusing on: connections between total income - needs - main factor of satisfaction - motivation - persons with whom they get along with - suggestions for hospital management - hospitals collaboration - etc. Also for future research the author recommends the use of quantitative analysis of the data by using econometric software such as STATA or SPSS.

Though a number of studies measuring the extent of certain factors that contribute to job satisfaction among members of medical institutions (Murray et al., 1986; Zellars et al., 2001; Janus et al., 2007; Peng et al., 2010; Kantsiper et al., 2009;) have been done, this study intends to lie a foundation for a more elaborate research that will utterly analyze the current situation in Romanian private and public medical institutions focusing on their human resource component and why medical personnel is 
becoming less humane by correlating the level of satisfaction with the emotional intelligence component.

\section{References}

Barhem, B., Younies, H. and Younis, M. (2010). Employee Satisfaction in the Health Care Sector: A comparative Study of Private and Public Health Care Organizations in PICBE | 417 the UEA. Journal of Health Management, 12(1), 20-37.

Dornescu, V. and Manea, T. (2013). Migratia Medicilori Romani: Dimensiuni socioDemografice si economice. Revista de Economie Sociala, 3(1), 122-138.

Hellman, C. (1997). Job satisfaction and intent to leave. Journal of Social Psychology, 137(6), 677-89.

Janus, K., Amelung, V.E., Gaitanides, M. and Schwartz, F.W. (2007). German physicians "on-strike"- shedding light on roots of physicians dissatisfaction. Health Pol., 82(1), 357-365.

Kantsiper, M.E., Ratanawongsa, N., Wright, S.M., Smith, C.G. and Levine, R.B. (2009). Factors that influence professional satisfaction in hospital medicine: A review for prospective hospitals. Journal of Hospital Medicine, 4(3), 23-28.

Khurshid, K., Abd, R., Merchant, J. and Hirani, D. (2005). Registered Nurses Perception of Work Satisfaction at a Tertiary Care University Hospital. Journal of Nursing Management, 13(1), 32-40.

Manu, F. (2015, August 24). Sistemul medical cu salarii la nivel occidental: cine sunt investitorii in sanatatea private romaneasca. Retrieved from http://adevarulfinanciar.ro/articol/sistemul-medical-cu-salarii-la-niveloccidental-cine-sunt-investitorii-in-sanatatea-privata-romaneasca/

Murray, A., Montgomery, J.E., Chang, H., Rogers, W.H., Inui, T., and Safran, D.G. (1986). Doctor Discontent A Comparison of Physician Satisfaction in Different Delivery System Settings, 1986 and 1997. J. Gen. Int. Med., 16(7) 452-459.

Peng, W., John, J. and lowler, K. (2010). Work-family conflict, self-efficacy, job satisfaction, and gender: Evidence from Asia. J. Leadersh. Organ.Stud., 17(13) 298308.

Strachota, E., Normandin, P., O’Brien, N., Clary, M. and Krukow, B. (2003). Reasons registered nurses leave or change employment status. Journal of Nursing Administration, 33(2), 111-17.

Timmreck, T.C. (2001). Managing motivation and developing job satisfaction in the health care work environment. The Health Care Manager, 20(1), 42-58.

Zellars, K.L., Hochwarter, W.A., Perrewé, P.L., Miles, A.K., and Kiewitz, C. (2001). Beyond self-efficacy: Interactive effects of role conflict and perceived collective efficacy. Journal of Managerial Issues, 12(4), 483-499. 